\title{
Color Doppler study of uterine vasculature in pregnancy induced hypertension
}

\author{
Shrirame D.V ${ }^{1}$, Kashyap H. K ${ }^{2}$, Behera R.C ${ }^{3}$, Sachdev Y.P \\ ${ }^{1}$ Dr. Deepti V. Shrirame, Junior Resident, ${ }^{2}$ Dr. H. K. Kashyap, Professor, ${ }^{3}$ Dr. R.C. Behera, Professor and HOD, all \\ above authors are affiliated with dept of Obstetrics \& Gynecology, ${ }^{4}$ Dr. Y.P. Sachdev, Associate Professor, Department \\ of Radio diagnosis, RMC, Loni, Maharashtra, India.
}

Corresponding Author: Dr. Deepti V. Shrirame, Email: drdeeptivs@gmail.com

\begin{abstract}
Objectives: 1. To study the blood flow pattern of uterine vessels in pregnancy induced hypertension by Color Doppler.2. To assess the predictive value of Color Doppler Studies of uterine blood flow patterns for perinatal outcome. Materials and Methods: The period of our study was for 2 years at a tertiary care hospital in rural area in RMC Loni. 50 cases diagnosed as pregnancy induced hypertension beyond 28 weeks of gestation, i.e, period of viability of fetus were screened by Color Doppler for uterine artery during the above-mentioned period. Outcome of these pregnancies was then collected. It included the gestational age of delivery, mode of delivery, birthweight, APGAR score, still births andlivebirths. Results: In this study birth weight in grams in $>36$ weeks gestation at delivery showed highly significant difference between the present $(1767+209.83)$ and absent $(2289.98+358.96)$ diastolic notch group indicating that birth weight of the neonate was affected by the presence of diastolic notch. Similarly neonatal mortality was more $(45.45 \%)$ in case of patients with presence of uterine artery diastolic notch as compared to absence of diastolic notch (0) which was statistically significant. Morbidity was $36.36 \%$ in diastolic notch group as compared to diastolic notch absent group (14.28\%). Conclusion: Doppler is an excellent armamentarium in the hands of obstetrician for non-invasive hemodynamic monitoring of PIH patients to identify the fetuses at risks and predicting perinatal morbidity and mortality. Doppler velocimetry gives us the idea about correct time of intervention so as to get good perinatal outcome thus preventing high fetal mortality and morbidity in hypertensive patients.
\end{abstract}

Key words: Color Doppler, Pregnancy induced hypertension, Uterine vasculature.

\section{Introduction}

One of the major concerns of obstetrical practice involves evaluation of fetal well-being. However, the relatively inaccessible fetal location and a dearth of appropriate diagnostic techniques have limited antepartum surveillance to fetal heart rate monitoring and sonographic biophysical assessment. Recent advances in the Doppler ultrasound technology offer a unique opportunity to extend our ability to investigate the fetal hemodynamic state [1]. Doppler ultrasound velocimetry has already been widely used for assessing cardiac structure and function and for determining circulatory insufficiency in peripheral vascular disease. Recently, the technique has been applied extensively to investigate fetal, feto-placental and utero-placental circulation and there is ample evidence associating abnormal Doppler findings with complications of

Manuscript received: $4^{\text {th }}$ January 2018

Reviewed: $14^{\text {th }}$ January 2018

Author Corrected: $22^{\text {nd }}$ January 2018

Accepted for Publication $27^{\text {th }}$ January 2018 pregnancy and an adverse perinatal outcome [2]. Application of Doppler ultrasound is not new in obstetrical practice; it has been in use for many years for detecting fetal heart activity and counting the fetal heart rate. however, this level of technology generates only Doppler audio output. Doppler ultrasound velocimetry, however requires extraction and further processing, depending upon the type of Doppler ultrasound. A basic understanding of the technology is essential for any meaningful evaluation of its utility and its limitations. Pregnancy induced hypertension (PIH) is defined as blood pressure recording of $140 / 90 \mathrm{~mm}$ of $\mathrm{Hg}$ on two occasions more than 6 hours apart after 20 weeks of gestation associated with or without proteinuria and/or edema [3]. Doppler Ultrasound instrumentation provides a noninvasive method of studying the status of various blood vessels which is very useful in cases of PIH. It provides a spectrum analysis of the velocities of moving red blood cells 
Original Research Article

thusgiving useful and important information in a variety of gynecologic and obstetric conditions. In obstetrics, "Doppler Velocimetry" of the utero-placental and fetoplacental circulation can be used to further investigate complications of pregnancy such as fetal growth retardation, other forms of fetal distress that result from fetal hypoxemia or asphyxia, fetal cardiac anomalies and/or cord malformation[4].

The aim of this study to publish in scientific journal is to vehemently emphasize the great utility of Color Doppler in PIH as the quickest, most reliable, noninvasive and repetitive modality to assess fetal wellbeing and take immediate decision regarding management thus saving precious lives.

\section{Aims and Objectives}

1.To study the blood flow pattern of uterine vessels in pregnancy induced hypertension by Color Doppler.

2.To assess the predictive value of Color Doppler Studies of uterine blood flow patterns for perinatal outcome.

\section{Material and Methods}

1. The period of our study extended up to 2 years at a tertiary care hospital in rural area in Rural Medical College, Loni, district Ahmednagar, Maharashtra, India.

2. During this period Dopplervelocimetry was performed at our institution.

3. Approval for this work was obtained from the institutional research committee

4. Informed consent was obtained from each woman studied.

5. Equipment: GE LOGIQ 400 PRO-3.5MHz Convex probe with pulsed wave and color Doppler.

6. 50 cases diagnosed as pregnancy induced hypertension beyond 28 weeks of gestation, i.e period of viability of fetus by Color Doppler during the above mentioned period.

7. The patients were followed up antenatally from time of detection till the time of delivery.

8. Outcome of these pregnancies was then collected.It included the gestational age of delivery,mode of delivery, birth weight, APGAR score, still births and live births

\section{Methods}

The pregnant women assumed a supine slightly tilted position.A coupling jelly was placed upon the abdomen, and the Doppler probe was placed. The uterine artery was located by B mode real time scanner and then color was displayed. The flow velocity wave forms were examined visually and quantitated by the use of the v-max v- min, systolic/diastolic ratio, pulsatility index, resistance index, diastolic notch and diastolic flow.

Inclusion criteria: regnant women having pregnancy induced hypertension beyond 28 weeks gestation were included in the study with blood pressure>- 140/90 $\mathrm{mm} \mathrm{Hg}$ with or without proteinuria.

\section{Exclusion criteria}

1. Antenatal cases with gestational age $<28$ weeks.

2. Normal routine antenatal case.

3. Multiple pregnancy.

4. Extra uterine pregnancy.

5. Antenatal cases with intrauterine fetal death.

6. Pregnancy with severe congenital anomaly.

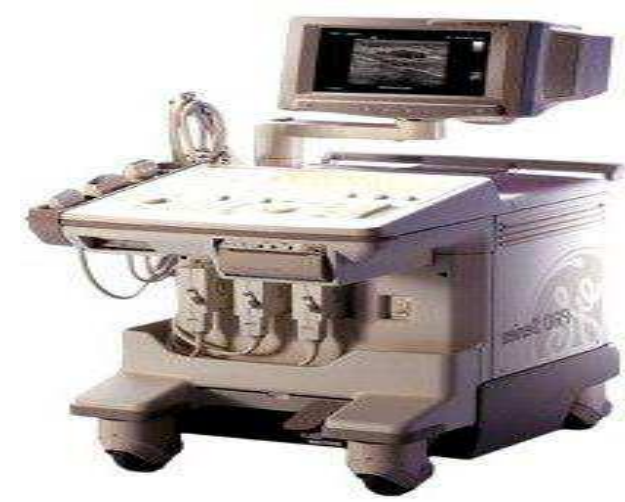

Equipment: GE LOGIQ 400 PRO-3.5MHz Convex probe with pulsed wave and color Doppler 
Original Research Article

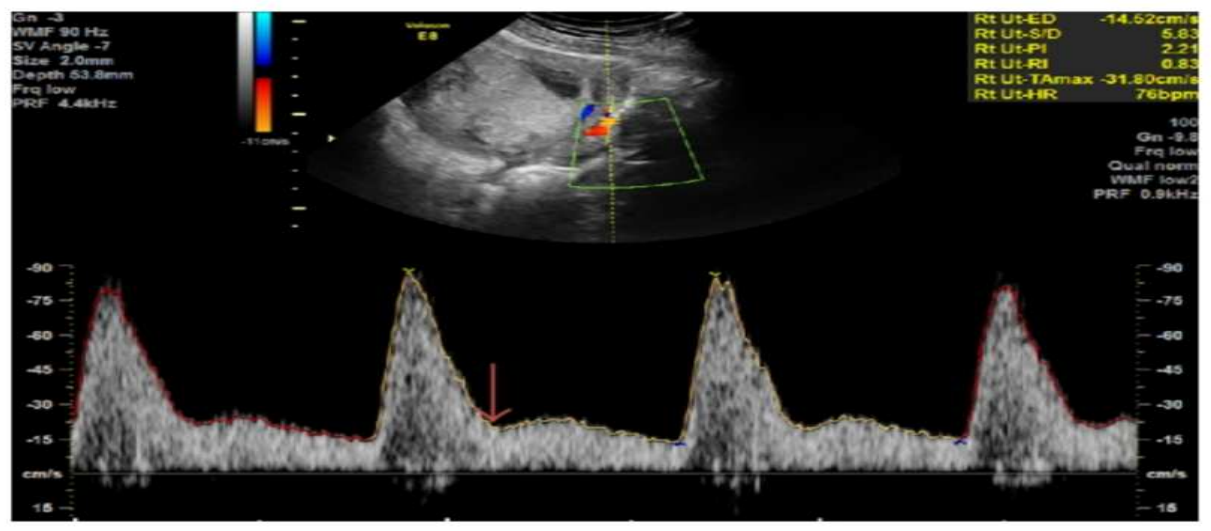

Uterine artery wave form with diastolic notch

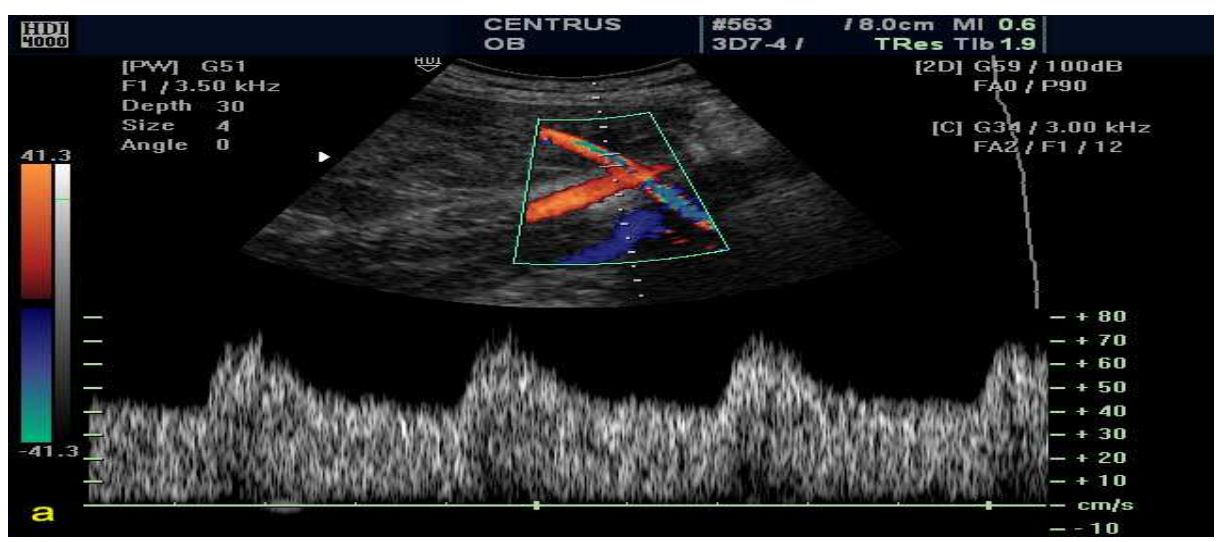

Normal uterine artery flow velocity wave form

\section{Observations and Results}

Table No-1: Age wise distribution of study population

\begin{tabular}{|c|c|}
\hline Age(years) & No of patients\% \\
\hline$<20$ & 8 \\
\hline $20-24$ & 64 \\
\hline $25-29$ & 26 \\
\hline $30 \&$ above & 2 \\
\hline
\end{tabular}

The above table shows that maximum caseswere in the age group of 20-24 years.

Table No.-2: Gravidity wise distribution of study population

\begin{tabular}{|c|c|}
\hline Gravida & No of patients\% \\
\hline Primi & 56 \\
\hline Multi & 44 \\
\hline
\end{tabular}

$56 \%$ cases were primigravida as per the above table.

Table No.-3: Severity of pregnancy induced hypertension wise distribution of study population.

\begin{tabular}{|c|c|}
\hline Severity of pregnancy induced hypertension & No of patients\% \\
\hline Mild & 54 \\
\hline Severe & 46 \\
\hline
\end{tabular}

The above table indicates that $54 \%$ cases were of mild $\mathrm{PIH}$ and $46 \%$ severe $\mathrm{PIH}$ 
Original Research Article

Table No.-4: Group with presence of diastolic notch in uterine artery

\begin{tabular}{|c|c|c|c|c|c|c|c|c|c|c|c|c|c|}
\hline \multirow{3}{*}{ 壱 } & \multirow{3}{*}{ 롤 } & \multirow{3}{*}{ 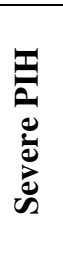 } & \multirow{3}{*}{ 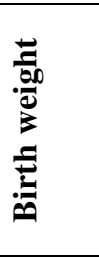 } & \multirow{3}{*}{ 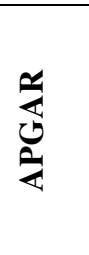 } & \multirow{3}{*}{ 号 } & \multirow{3}{*}{ 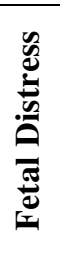 } & \multicolumn{4}{|c|}{ Mode of delivery } & \multicolumn{3}{|c|}{$\begin{array}{c}\text { peri-natal out } \\
\text { come }\end{array}$} \\
\hline & & & & & & & \multicolumn{2}{|c|}{ vaginal } & \multicolumn{2}{|c|}{ Caesarean } & \multirow[b]{2}{*}{ 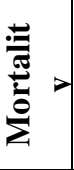 } & \multirow[b]{2}{*}{$\frac{\overrightarrow{0}}{\stackrel{0}{0}}$} & \multirow[b]{2}{*}{ ‡్ } \\
\hline & & & & & & & $\begin{array}{c}\text { Spont } \\
\text { aneou } \\
\text { s }\end{array}$ & $\begin{array}{c}\text { indu } \\
\text { ced }\end{array}$ & $\begin{array}{c}\text { electi } \\
\text { ve }\end{array}$ & $\begin{array}{l}\text { Emer } \\
\text { gency }\end{array}$ & & & \\
\hline $\begin{array}{c}<34 \\
\text { weeks }\end{array}$ & 0 & 9 & 1.325 & $3,5,6$ & 0 & 2 & 2 & 1 & 1 & 5 & 5 & 3 & 1 \\
\hline $\begin{array}{r}34-36 \\
\text { weeks }\end{array}$ & 3 & 5 & 1.893 & $5,7,8$ & 0 & 0 & 2 & 2 & 0 & 4 & 2 & 3 & 3 \\
\hline $\begin{array}{c}>36 \\
\text { weeks }\end{array}$ & 2 & 2 & 1.766 & $6,7,8$ & 1 & 2 & 1 & 0 & 1 & 3 & 3 & 2 & 0 \\
\hline
\end{tabular}

Group with presence of diastolic notch had 10 cases of perinatal mortality and 8 cases of perinatal morbidity

Table No.-5: Group with absence of diastolic notch in uterine artery.

\begin{tabular}{|c|c|c|c|c|c|c|c|c|c|c|c|c|c|}
\hline \multirow{3}{*}{ 莺 } & \multirow{3}{*}{ 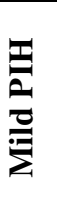 } & \multirow{3}{*}{ 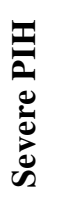 } & \multirow{3}{*}{ 釆 } & \multirow{3}{*}{$\begin{array}{l}\frac{4}{4} \\
\vdots \\
\qquad\end{array}$} & \multirow{3}{*}{ 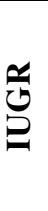 } & \multirow{3}{*}{ 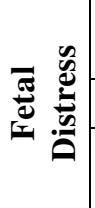 } & \multicolumn{4}{|c|}{ Mode of delivery } & \multicolumn{3}{|c|}{$\begin{array}{c}\text { peri-natal out } \\
\text { com }\end{array}$} \\
\hline & & & & & & & \multicolumn{2}{|c|}{ vaginal } & \multicolumn{2}{|c|}{ Caesarean } & \multirow{2}{*}{$\stackrel{\bar{\Xi}}{\Sigma}$} & \multirow{2}{*}{ 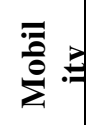 } & \multirow{2}{*}{ 竞 } \\
\hline & & & & & & & $\begin{array}{r}\text { Sponta } \\
\text { neous }\end{array}$ & $\begin{array}{c}\text { indu } \\
\text { ced }\end{array}$ & $\begin{array}{l}\text { electi } \\
\text { ve }\end{array}$ & $\begin{array}{l}\text { Emer } \\
\text { gency }\end{array}$ & & & \\
\hline $\begin{array}{c}<34 \\
\text { weeks }\end{array}$ & 1 & 2 & 1.66 & $6,6,7$ & 0 & 0 & 0 & 3 & 0 & 0 & 0 & 1 & 2 \\
\hline $\begin{array}{l}\text { 34-36 } \\
\text { weeks }\end{array}$ & 9 & 1 & 2.26 & $4,7,8$ & 2 & 3 & 1 & 2 & 1 & 6 & 0 & 2 & 8 \\
\hline $\begin{array}{c}>36 \\
\text { weeks }\end{array}$ & 13 & 2 & 2.42 & $6,7,9$ & 1 & 1 & 7 & 0 & 1 & 7 & 0 & 1 & 14 \\
\hline
\end{tabular}

Group with absent diastolic notch had no perinatal mortality whereas 4 cases had perinatal morbidity.

Table No.-6: Comparison of mean birth weight in grams in present and absent uterine artery diastolic notch (DN) group.

\begin{tabular}{|c|c|c|c|c|c|}
\hline $\begin{array}{c}\text { Gestational age in weeks } \\
\text { at the time of delivery }\end{array}$ & $\begin{array}{c}\text { DN present } \\
(\mathbf{n = 2 2}) \\
\text { Mean+-SD }\end{array}$ & $\begin{array}{c}\text { DN Absent } \\
(\mathbf{n = 2 8}) \\
\text { Mean+- S/D }\end{array}$ & T value & P value & Result \\
\hline$<34$ & $\begin{array}{c}1329.33+-410.43 \\
(\mathrm{n}=9)\end{array}$ & $\begin{array}{c}1415.62+-248.7 \\
(\mathrm{n}=3)\end{array}$ & 0.53 & $\mathrm{p}>0.05$ & Not significant \\
\hline $34-36$ & $\begin{array}{c}1894.55+-526.44 \\
(\mathrm{n}=8)\end{array}$ & $\begin{array}{c}2104.26+-314.27 \\
(\mathrm{n}=10)\end{array}$ & 0.99 & $\mathrm{p}>0.05$ & Not significant \\
\hline$>36$ & $\begin{array}{c}1767.7+-209.83 \\
(\mathrm{n}=5)\end{array}$ & $\begin{array}{c}2289.98+-358.96 \\
(\mathrm{n}=15)\end{array}$ & 3.96 & $\mathrm{P}<0.01$ & Highly significant \\
\hline
\end{tabular}

Mean birth weight $>36$ weeks shows significant difference in present and absent uterine artery diastolic notch as per the above table.

Table No.-7 : Uterine artery diastolic notch (DN) and perinatal outcome

\begin{tabular}{|c|c|c|c|}
\hline Perinatal outcome & Present DN\% & Absent DN\% & After applying Z test, P value \\
\hline Morbidity & 36.36 & 14.28 & $\mathrm{P}<0.05$ \\
\hline Mortality & 45.45 & 0 & $\mathrm{P}<0.05$ \\
\hline
\end{tabular}

Perinatal morbidity and mortality in uterine artery diastolic notch is significantly more in cases with absent diastolic notch. 
Original Research Article

Table No-8: Uterine artery diastolic notch and its efficacy of prediction of poor perinatal outcome.

\begin{tabular}{|c|c|c|c|c|}
\hline Perinatal outcome & Sensitivity \% & Specificity \% & PPV \% & NPV \% \\
\hline Morbidity & 66.66 & 63.15 & 36.36 & 85.71 \\
\hline Mortality & 100 & 66.66 & 45 & 100 \\
\hline
\end{tabular}

Uterine artery diastolic notch has $100 \%$ sensitivity in mortality cases, $100 \%$ NPV in mortality cases and $85.71 \%$ NPV in morbidity cases.

\section{Discussion}

Hypertensive disorders complicating pregnancy are common and form a deadly triad along with hemorrhage and infection that contribute greatly to maternal morbidity and mortality. The incidence of various hypertensive disorders of pregnancy is around 5\% to $15 \%$. They are the most common cause of fetal growth retardation and preterm delivery and thus contributing to prenatal morbidity and mortality, the percentage being 15 to $20 \%$ in developing countries. There is evidence that such pregnancies are commonly associated with reduced utero-placental blood flow. This is thought to be due to the development of certain pathological obstructive lesions at the level of the spiral arteries [3].

The aim of this study was to study uterine vasculature by Color Doppler and to assess its predictive value regarding fetal outcome. A total of 50 cases were studied by Color Doppler who were diagnosed as pregnancy induced hypertension beyond 28 weeks of gestation, i.e; period of viability of fetus out of which 27 were mild PIH and 23 were severe. The target group for Doppler velocimetrystudy is the group with age between 20-24 years and primigravida as evidenced in observation tables 1 and 2 . In our study $64 \%$ cases were in the age group of 20 to 25 years comparable to the study by WHO (1998) which did a collaborative study of hypertensive disorders of pregnancy and concluded that preeclampsia occurs more commonly during first pregnancy and in very young or older women and when a woman has had preeclampsia in previous pregnancies [6]. In the study by Aharwal $\mathrm{S}$ et al $73.1 \%$ cases were found in 20-29 years age group [7].

In our study $54 \%$ had mild hypertension and $46 \%$ had severe hypertension. In the study by Gaikwad P R et al [8] there were 78.3 mild cases and 21.7 severe cases. In this study birth weight in $>36$ weeks gestation at delivery showed highly significant difference between the present $(1767+209.83)$ and absent $(2289.98+358.96)$ diastolic notch group indicating that birth weight of the neonate was affected by the presence of diastolic notch.
Similarly, neonatal mortality was more $(45.45 \%)$ in case of patients with presence of uterine artery diastolic notch as compared to absence of diastolic notch which was statistically significant similar to the study carried out by Fleisher et.al [9] and Aharwal S et al. Study by Gaikwad P R et al had perinatal death $8.1 \%$. Morbidity was $36.36 \%$ in diastolic notch group as compared to diastolic notch absent group (14.28\%). Thus the relationshipbetween abnormal uterine artery Doppler velocimetry and preeclampsia and adverse pregnancy outcome is well established[10]

\section{Conclusion}

1.Color Doppler is an excellent armamentarium in the hands of obstetrician for noninvasive hemodynamic monitoring of PIH patients to identify the fetuses at risksand predicting perinatal morbidity and mortality.

2. Dopplervelocimetry gives us the idea about correct time of intervention so as to get good perinatal outcome thus preventing high mortality and morbidity in hypertensive patients.

\section{Funding: Nil, Conflict of interest: None. Permission of IRB: Yes}

\section{References}

1. Carroll BA. Duplex Doppler Systems in obstetric ultrasound. Radiol Clin N Am.1990;25(1):189-202.

2. Hoffman C, Galan HL. Assessing the at risk, fetus: Doppler ultrasound. Curr Opin Obstet Gynaecol. 2009; 21: 161-166.

3. Chen F. Hypertensive disorders of pregnancy. Gynakol Geburtsmed Gynakol Endokrinol 2008; 4 (1): 24-34.

4. Kevin A, Mairi H, James P, Martin J, Pregnancy screening by Doppler uteroplacental and umbilical artery waveforms. Br J Obstetric Gynecology 1989, Oct; 96: 1163-67 
5. C J Bhatt, J Arora. Role of color Doppler in pregnancy induced hypertension (100 cases) IJRI 2003, Vol 13, 4, 417-420

6. Geographic variation in the incidence of hypertension in pregnancy. World Health Organization International Collaborative Study of Hypertensive Disorders of Pregnancy.Am J Obstet Gynecol. 1988 Jan;158(1):80-3.

7. Aharwal S, Agrawal R, Sharma S, A study of role of Doppler ultrasound in Pregnancy induced hypertension (PIH) and perinatal outcome: Int J Med Res Rev 2016; 4 (4): 673-680.doi: 10.17511/ijmrr.2016.i04.34.
8. Gaikwad PR et al. International Journal of Reproduction, Contraception, Obstetrics and Gynecology. 2017 Jun; 6 (6): 2354-2360

9. Fleischer A, Schulman H, Farmakides G, Bracero L, Grunfeld L, Rochelson B, Koenigsberg M. Uterine artery Doppler velocimetry in pregnant women with hypertension. Am J Obstet Gynecol. 1986 Apr;154 (4): 806-13.

10. Aquilina J, Harrington K. Pregnancy hypertension and uterine artery Doppler ultrasound. Curr Opin Obstet Gynecol. 1996 Dec;8(6):435-40.

\section{How to cite this article?}

Shrirame D.V, Kashyap H. K, Behera R.C, Sachdev Y.P. Color Doppler study of uterine vasculature in pregnancy induced hypertension. Int J Med Res Rev 2018;6(01):54-59. doi:10.17511/ijmrr. 2018.101.09. 